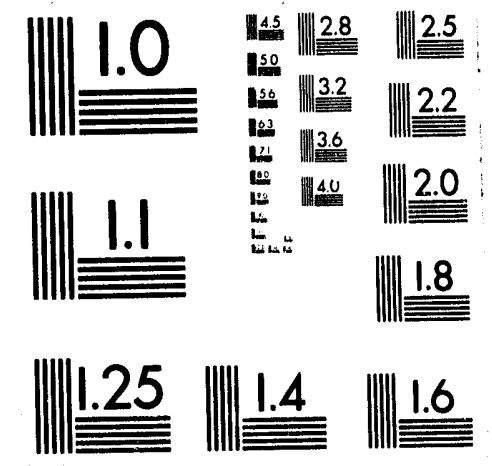



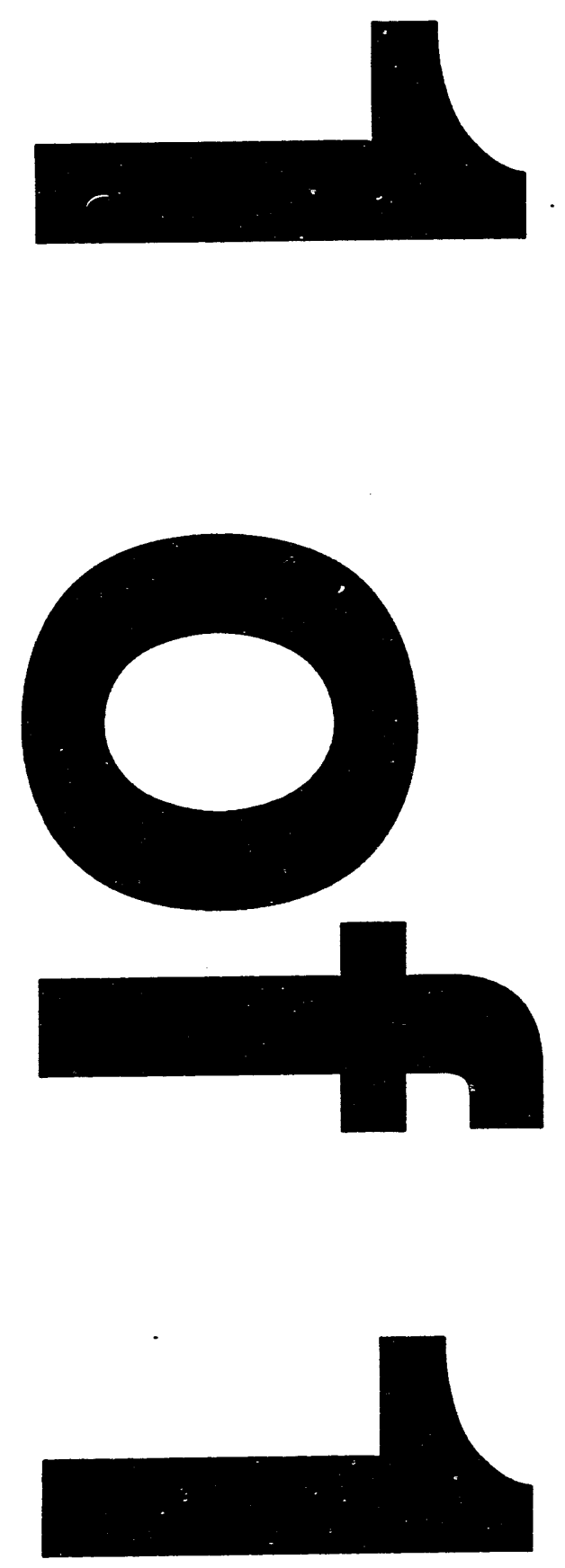
Instrumentation and Controls Division

\section{INSTRUMENT CALIBRATION PLAN OF THE TECHNICAL SUPPORT DEPARTMENT}

K. L. Allison

D. M. Duncan

T. J. McIntyre

A. J. Millet

T. E. Swabe

R. A. Vines

Date Published-November 1993

Prepared by the

OAK RIDGE NATIONAL LABORATORY

Oak Ridge, Tennessee 37831-6285 managed by

MARTIN MARIETTA ENERGY SYSTEMS, INC. for the

U.S. DEPARTMENT OF ENERGY under contract DE-AC05-84OR21400 
CONTENTS

Page

LIST OF FIGURES $\ldots \ldots \ldots \ldots \ldots \ldots \ldots \ldots \ldots \ldots \ldots \ldots \ldots \ldots$

ABSTRACT $\ldots \ldots \ldots \ldots \ldots \ldots \ldots \ldots \ldots \ldots \ldots \ldots \ldots \ldots \ldots \ldots \ldots$

1. INTRODUCTION $\ldots \ldots \ldots \ldots \ldots \ldots \ldots \ldots \ldots \ldots \ldots \ldots \ldots \ldots \ldots$

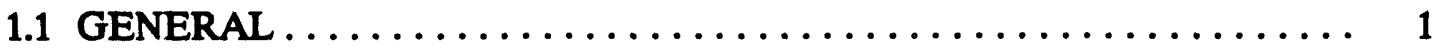

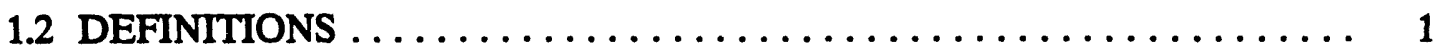

2. PROGRAM ORGANIZATION $\ldots \ldots \ldots \ldots \ldots \ldots \ldots \ldots \ldots \ldots \ldots$

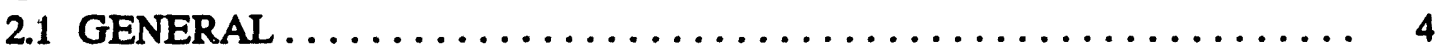

2.2 PROGRAM POLICY AND DIRECTIONS $\ldots \ldots \ldots \ldots \ldots \ldots \ldots \ldots \ldots$

2.3 PROGRAM ELEMENTS $\ldots \ldots \ldots \ldots \ldots \ldots \ldots \ldots \ldots \ldots \ldots \ldots \ldots \ldots$

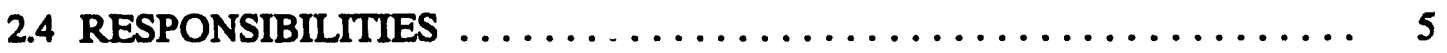

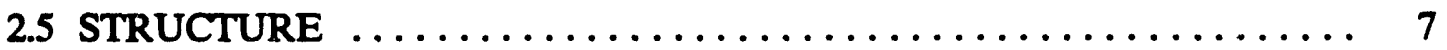

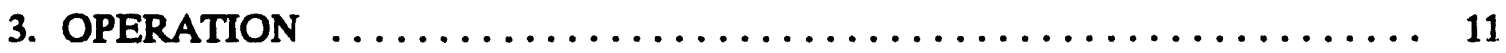

3.1 CALIBRATION $\ldots \ldots \ldots \ldots \ldots \ldots \ldots \ldots \ldots \ldots \ldots \ldots \ldots \ldots \ldots$

3.2 EXCEPTIONS TO PERIODIC CALIBRATION REQUIREMENTS . . . 12

3.3 LIMITED CALIBRATION $\ldots \ldots \ldots \ldots \ldots \ldots \ldots \ldots \ldots \ldots \ldots \ldots \ldots \ldots \ldots$

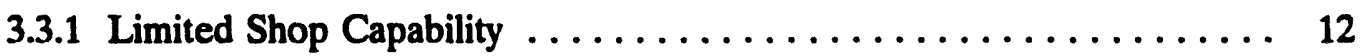

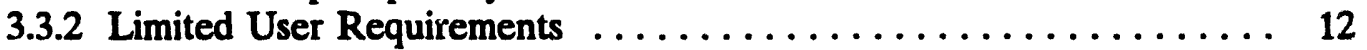

3.3.3 Instrument Limitation $\ldots \ldots \ldots \ldots \ldots \ldots \ldots \ldots \ldots \ldots \ldots \ldots \ldots \ldots \ldots$

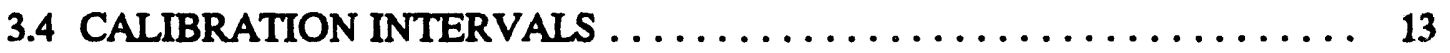

3.5 CALIBRATION GRACE PERIOD $\ldots \ldots \ldots \ldots \ldots \ldots \ldots \ldots \ldots \ldots \ldots \ldots$

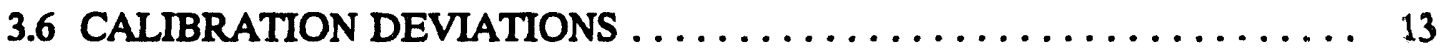

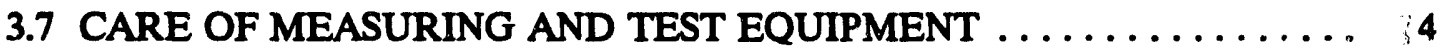

3.8 MEASURING AND TEST EQUIPMENT WARRANTIES . . . . . . . . 14

4. CALIBRATION LABELS AND FORMS $\ldots \ldots \ldots \ldots \ldots \ldots \ldots \ldots \ldots$

4.1 PREPARATION AND USE OF CALIBRATION FORMS

AND LABELS $\ldots \ldots \ldots \ldots \ldots \ldots \ldots \ldots \ldots \ldots \ldots \ldots \ldots \ldots \ldots \ldots \ldots \ldots$

4.2 MEASURING AND TEST EQUIPMENT CALIBRATION LABEI . . . . 5

4.3 PLACEMENT OF CALIBRATION LABELS $\ldots \ldots \ldots \ldots \ldots \ldots \ldots \ldots \ldots$

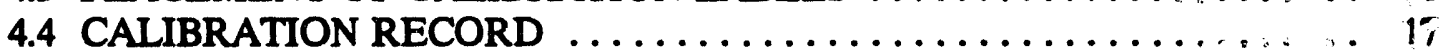

4.5 MEASURING AND TEST EQUIPMENT CALIBRATION CORRECTION RECORD $\ldots \ldots \ldots \ldots \ldots \ldots \ldots \ldots \ldots \ldots \ldots \ldots \ldots, 18$

4.6 COMPUTERIZED AND MANUALLY PREPARED CALIBRATION DATA $\ldots \ldots \ldots \ldots \ldots \ldots \ldots \ldots \ldots \ldots \ldots$

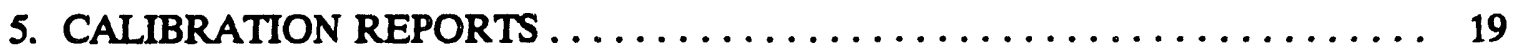

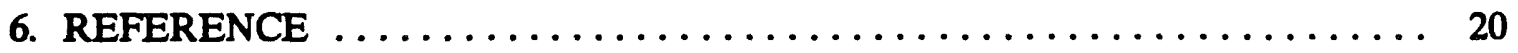




\section{LIST OF FIGURES}

Page

1. Measurement traceability of the Calibration Program $\ldots \ldots \ldots \ldots \ldots \ldots \ldots$

2. Calibration job flow $\ldots \ldots \ldots \ldots \ldots \ldots \ldots \ldots \ldots \ldots \ldots \ldots$

3. Flow of the calibration process after the custodian decides that M\&TE requires calibration $\ldots \ldots \ldots \ldots \ldots \ldots \ldots \ldots \ldots \ldots \ldots \ldots$

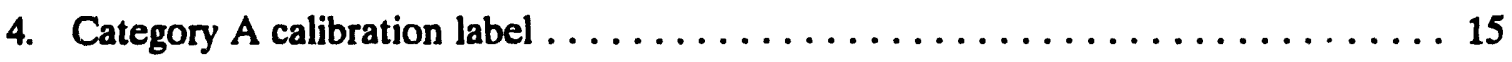

5. Category $B$ calibration label $\ldots \ldots \ldots \ldots \ldots \ldots \ldots \ldots \ldots \ldots \ldots \ldots \ldots \ldots \ldots \ldots \ldots \ldots$

6. Category $\mathrm{C}$ calibration label $\ldots \ldots \ldots \ldots \ldots \ldots \ldots \ldots \ldots \ldots \ldots \ldots \ldots \ldots \ldots \ldots \ldots \ldots \ldots$

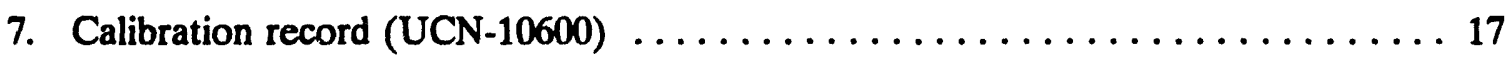


This document describes the management of the Calibration Program of the Instrumentation and Controls Division's Technical Support Department (TSD). The implementation of the program is the responsibility of TSD; however, the decision as to whether or not equipment is calibrated is the responsibility of the end user. It is imperative that all parties maintain timely and effective dialogue to ensure that the process is adequate to meet the needs of Oak Ridge National Laboratory (ORNL). The program is a planned, systematic schedule of actions necessary to provide confidence that equipment used to make measurements or quality judgments conforms to established technical requirements and is traceable to nationally recognized standards.

It is especially important to place this guidance in the context for which it is intended. ORNL instrumentation support at the shop and facility level is the primary application. Energy Systems and site policy provide the umbrella guidance needed for overall measuring and test equipment support.
\end{abstract}




\section{INTRODUCTION}

This document describes the methods and procedures for management of the Oak Ridge National Laboratory (ORNL) Instrumentation \& Controls (I\&C) Division Technical Support Department (TSD) Calibration Program. All personnel who have responsibility for calibration of equipment shall be familiar with the calibration program described in this document.

\subsection{GENERAL}

The primary function of the TSD Calibration Program is to ensure the measurement integrity of all instruments used to provide quantitative or qualitative data to meet program objectives and to ensure safe, reliable, cost-effective, and timely operation.

The TSD Calibration Program includes measurement standards and equipment, technical personnel, TSD work centers, measurement equipment users, calibration data, and integrated planning combined in a structured program to ensure the reliability and accuracy of instruments, systems, subsystems, and equipment.

The Calibration Program is a planned, systematic schedule of actions necessary to provide confidence that equipment used to make measurements or quality judgments conforms to established technical requirements. It ensures measurement traceability to the National Institute of Standards and Technology (NIST) or other nationally recognized standards. Measurements in the mechanical, electrical, electronics, chemical, and nuclear fields are included.

The contents of this document are reviewed and revised triennially by the calibration committee appointed by the TSD department head. The plan is distributed according to the current distribution list at the end of this document.

\subsection{DEFINITIONS}

The following definitions are provided to ensure uniform understanding of selected terms as they are used in this document.

A. Calibration: The process of comparing the response of some instrument or system to a standard instrument or system over some measurement range.

B. Calibration (limited): Calibration of measuring and test equipment (M\&TE) at a level of accuracy less than that specified in the authorized calibration procedure or M\&TE manufacturer's specifications but at an acceptable level for its intended use or less than all functions or ranges on a multifunction instrument.

C. Calibration record: Record prepared for a specific item to show the actual value of the parameter(s) calibrated.

D. Correction table: Table of values prepared for a specific item to show the corrections necessary to obtain actual values. 
E. Equipment types:

1. Measuring and test equipment (M\&TE): M\&TE includes all tools, gauges, instruments, devices, or systems used to inspect, test, calibrate, measure, or troubleshoot in order to control or acquire data for verifying the conformance of an instrument or piece of equipment to specified requirements. M\&TE does not include test equipment used for preliminary checks where data obtained will not be used to determine acceptability or verify conformance to established criteria.

2. Fundamental standard: Of or related to a well-defined, naturally occurring process or one that is premised on basic physical principles (e.g., speed of light in vacuum, electron charge, triple point of water, etc.).

3. Laboratory standard: An instrument which is calibrated periodically against a primary standard and which serves as the highest level standard for a particular calibration organization.

4. Primary standard: The highest level measurement standard to which all other standards are traceable. There are three primary standards (e.g., cesium beam clock, triple point of water, and platinum-irridium mass artifact) which are maintained at national or internationally recognized standards laboratories.

5. Transfer standard: A laboratory instrument which is used to calibrate working standards and which is calibrated periodically against the laboratory standard.

6. Working standard: An instrument that is calibrated in a laboratory against a transfer standard or laboratory standard and is used as a standard for calibrating measuring, test, or process instrumentation.

7. Equipment not requiring calibration: Equipment that does not require calibration or other comparison traceable to nationally recognized standards.

F. Custodian/user: Person or organization responsible for the use and care of a specific instrument.

G. Work centers: Maintenance shops responsible for repairing and calibrating M\&TE.

H. Metrology: The science of measurement. In general, the application of measurement science includes knowledge of standards of measurement, measurement units, frames of reference, environmental conditions, experimental techniques, statistical analysis, and reporting of data.

I. Metrology Research and Development Laboratory (MRDL): A facility operated by the I\&C Division engineering and research staff which provides standards and traceability to the maintenance of all electrical and physical standards at ORNL. In addition, metrology engineering support is provided to the TSD through development of policies, procedures, and training media as well as consultation of the development of experimental methodologies for performing maintenance and calibration activities. 
J. Traceability: Ability to relate individual measurement results to national standards or nationally accepted measurement systems through an unbroken chain or direct comparison.

K. Instrument accuracy. The degree of conformity of a measure to a standard or true value as determined via calibration. Measurement system accuracy may include, but is not limited to, instrumental accuracy (both bias and precision errors), measurement techniques accuracy (thermal emfs, loose connections, etc.), and statistical analysis accuracy (data reduction errors such as rounding off or approximations).

L. In calibration: A device is assumed to be in calibration when it has an unexpired calibration label and the device shows no signs of having been subjected to abuse or an environment that may have invalidated its calibration.

M. Calibration categories (as defined by QA-IC-12):

Category A: Devices and systems that are not to be calibrated.

Category B: Devices and systems that are to be included in a calibration recall program on a regular cycle.

Category C: Devices and systems that are to be calibrated by or at the direction of the user. 


\section{PROGRAM ORGANIZATION}

\section{GENERAL}

The purpose of the TSD calibration plan is to provide a uniform and documented calibration program to ensure that all M\&TE used in support of ORNL systems and experiments is maintained at a high level of confidence. The plan states the basic elements of a comprehensive control and calibration program. The responsibilities of TSD calibration shops and personnel, the Metrology Laboratory, and the custodian/user are also identified.

\section{PROGRAM POLICY AND DIRECTIONS}

This plan complies with and expands upon DOE Order 4330.4A (Maintenance Management Program) and ORNL quality assurance procedures that define the requirements for effective control and calibration of M\&TE.

\section{PROGRAM ELEMENTS}

A comprehensive control and calibration program for M\&TE should include the following basic elements:

A. A current master equipment list utilizing a unique number identification system and a computerized data base for storing equipment history.

B. Calibration standards traceable to nationally recognized standards.

C. Provisions for identifying limitations in the use of M\&TE items not fully calibrated.

D. Use of documented, reviewed, and approved procedures by knowledgeable technicians.

E. Methodology for handling M\&TE determined to be out of calibration, defective, or unreliable.

F. Acquisition and control of operating and technical manuals for M\&TE.

G. Selection, maintenance, and documentation of suitable equipment necessary to maintain an effective calibration program.

H. Training for all personnel that perform calibration tasks. 


\section{RESPONSIBIITIES}

A. Technical Support Department

1. Provides training to ensure that technicians performing calibrations have adequate knowledge and use approved procedures.

2. Maintains the Maintenance Accountability, Jobs, and Inventory Control (MAJIC) System, specified in Sect. 10 of the Maintenance Information and Data Acquisition System (MIDAS) information system. MIDAS is a data base system that contains the M\&TE master equipment list, service records, and status reports and provides for scheduling of equipment on calibration recall.

3. Maintains working standards and ensures measurement traceability to NIST or other nationally recognized standards.

B. Metrology Laboratory

1. Maintains reference standards and ensures measurement traceability to nationally recognized standards and provides specialized services for calibration of unique equipment.

2. Provides calibration services for working and transfer standards to TSD in support of maintenance activities.

3. Provides metrology engineering services to TSD which includes policy, procedure, and training media development as well as consultation on the development of experimental methodologies for performing maintenance and calibration activities.

4. Provides metrology engineering and measurement systems development to all ORNL divisions as requested.

C. Shop Supervisor/Technical Support

1. Assists in evaluating calibration data and prepares correction charts if necessary or requested.

2. Implements the TSD Calibration Program.

3. Reviews for adequacy and authorizes the use of manufacturers' calibration procedures when TSD procedures are unavailable.

4. Prepares calibration procedures for M\&TE when existing procedures are determined to be inadequate or unavailable.

5. Updates the M\&TE master equipment list and maintains calibration records for equipment calibrated. 
6. Notifies custodian/user when out-of-tolerance conditions occur.

7. Ensures that personnel performing calibrations on M\&TE are familiar with the calibration plan and that personnel training is documented in the TSD training data base.

8. Ensures that "as-found" and "as-left" calibration data are documented, stored, and readily retrievable.

9. Ensures that calibration information for each calibration activity is provided to the custodian/user upon request.

10. Ensures that TSD working standards are traceable directly to nationally recognized standards.

D. Technician

1. Verifies that standards are within the current calibration interval and in good working condition before use.

2. Checks operational performance and records "as-found" data.

3. If "as-found" data indicate out-of-tolerance condition, adjustments are performed and "as-left" data are recorded.

4. Prepares calibration and correction charts when appropriate.

5. Shall be aware of system requirements and report any discrepancies.

6. Shall report to the facility manager and shop supervisor out-of-tolerance conditions.

E. Custodian/User

The responsibilities of the custodian/user are defined in QA-L-12-100 and are listed in this plan for reference purposes only.

1. Identifies equipment classified as M\&TE. Reviews the application of M\&TE for proper type, range, accuracy, and tolerance with the Quality Assurance Specialist (QAS) and the appropriate calibration organization.

2. Categorizes the M\&TE as A, B, or C.

3. For category B M\&TE, in consultation with the appropriate calibration organization, agrees on calibration procedures, certification range, recalibration and preventive maintenance interval, and accuracy to be achieved.

4. Affixes category $\mathrm{A}$ (when required) and category $\mathrm{C}$ calibration labels. 
5. Ensures that adequate calibration data records are maintained for M\&TE.

6. Ensures that out-of-calibration M\&TE devices are tagged and/or segregated and not used until recalibrated.

7. Evaluates and documents the validity of previous inspection or test results and the acceptability of items when M\&TE is found to be out of tolerance.

\section{STRUCTURE}

The TSD Calibration Program involves all persons who use M\&TE in their work. The first responsibility is on the M\&TE custodian/user, who must ensure that all M\&TE used to generate quality data is "in calibration."

Figure 1 depicts the measurement traceability of the Calibration Program. A calibration operation should be performed in an environment as close to end use as possible. Instruments in work centers are calibrated in a centralized calibration facility or in the MRDL. Centralized calibration standards are calibrated by the MRDL or other authorized calibration facilities which maintain reference standards of known accuracy traceable to nationally recognized standards.

Functions such as instrument recall, data analysis, calibration procedure development, and state-of-the-art advancements must be included in any calibration program plan. The flow of the TSD instrument calibration program (Fig. 2) provides centralized control and surveillance. Figure 3 depicts the flow of the calibration process after the custodian decides that M\&TE requires calibration. 


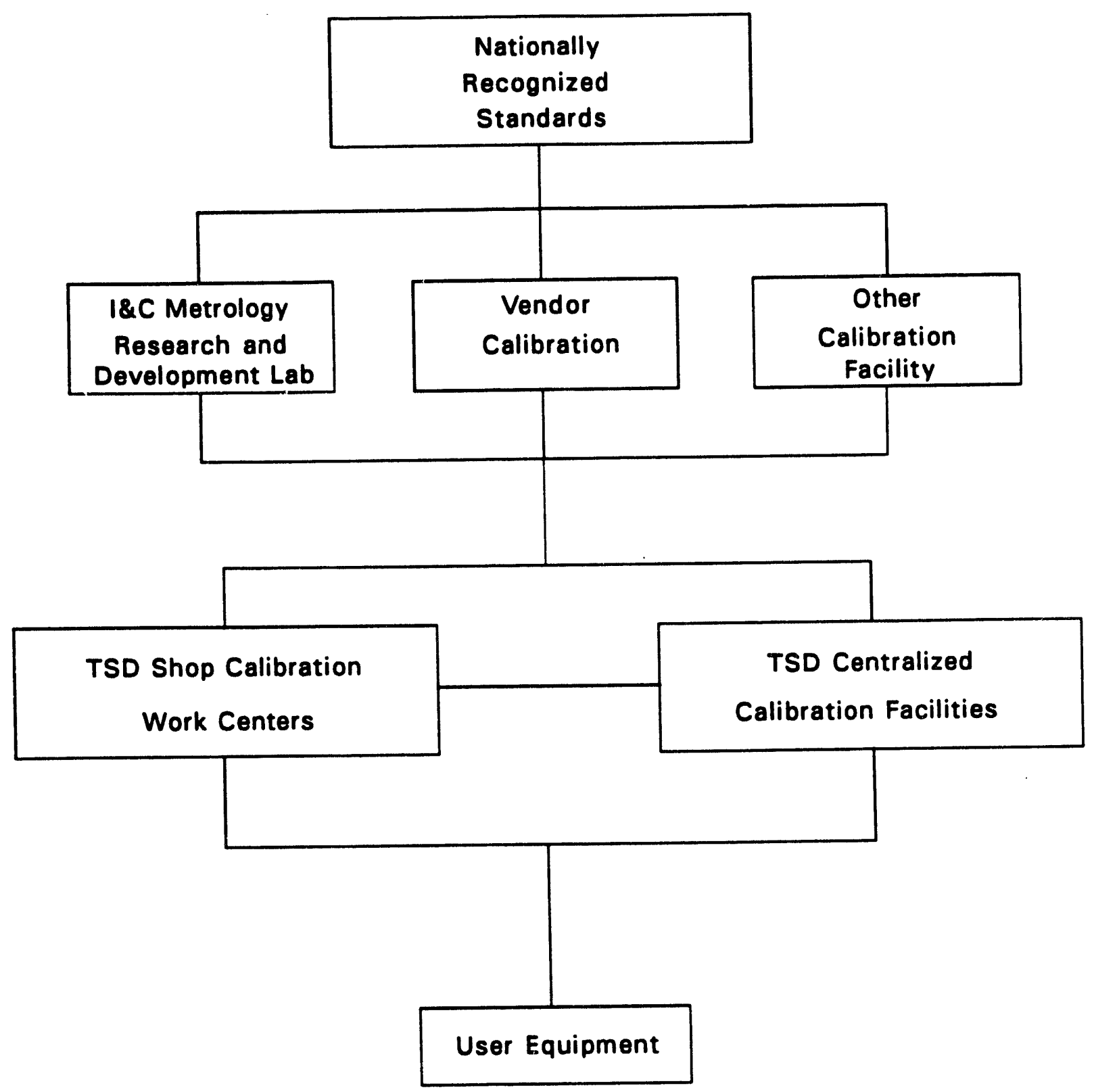

Fig 1. Measurement traceability of the Calibration Program. 


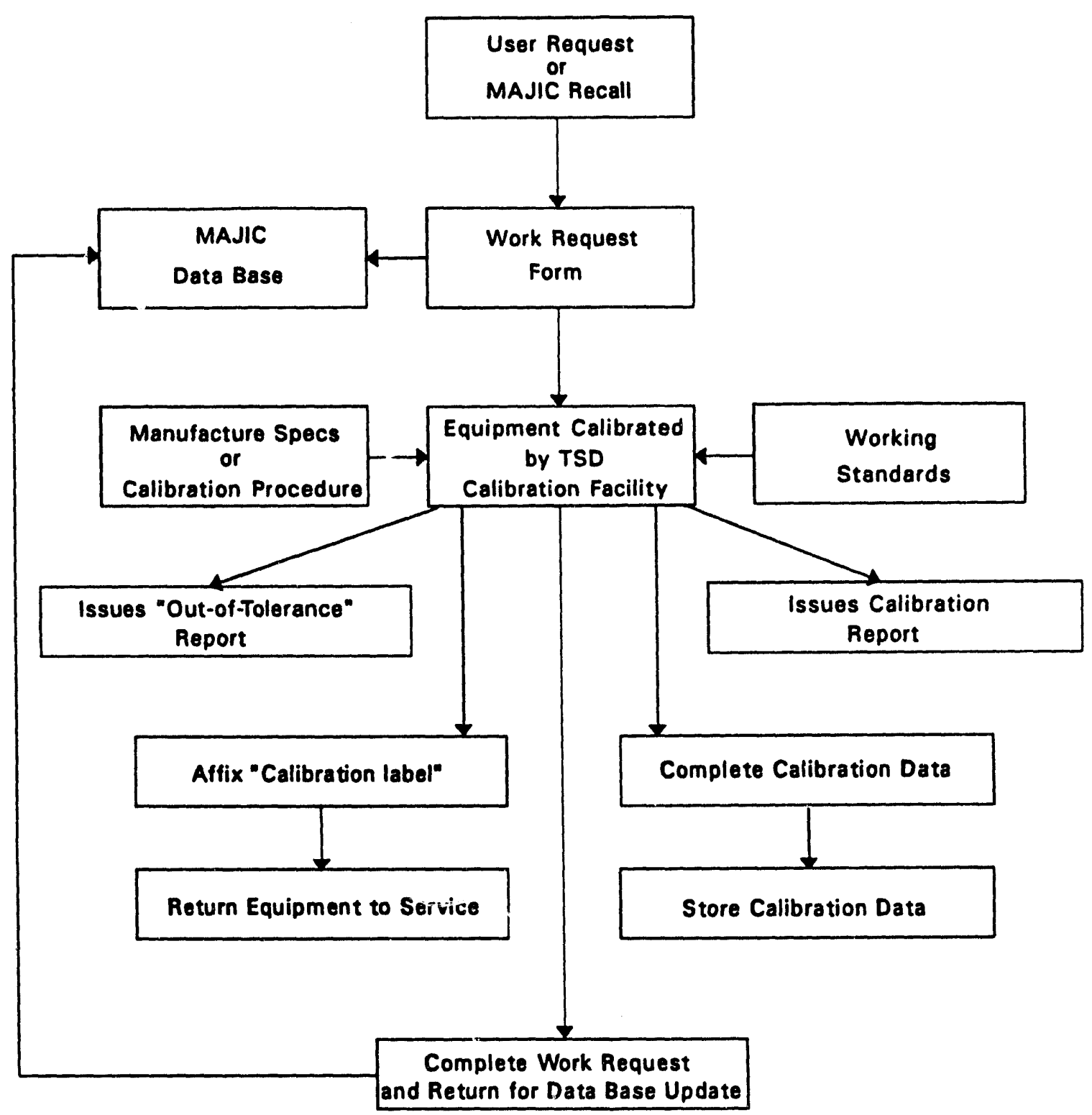

Fig. 2. Calibration job flow. 


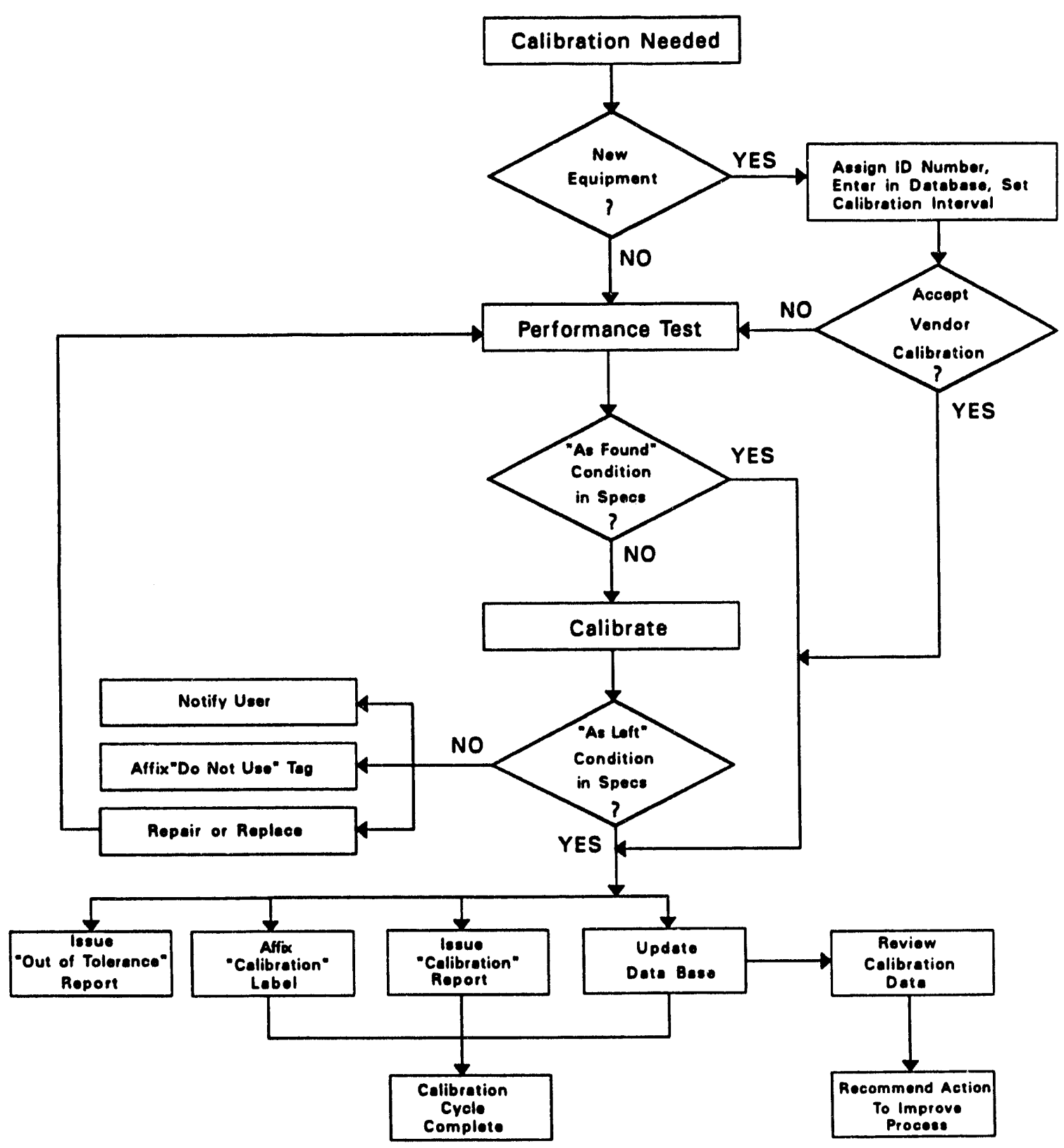

Fig. 3. Flow of the calibration process after the custodian decides that M\&TE requires calibration. 


\section{OPERATION}

\subsection{CALIBRATION}

Maintenance shops, which are staffed and operated by the TSD, are responsible for repairing and/or calibrating all M\&TE assigned to their area of responsibility. Calibration intervals and responsibilities for maintenance or calibration are identified in this document. M\&TE that is not used to make measurements critical to the test and alignment of operational systems and equipment is calibrated at specific intervals or before use.

A. To ensure a valid and accurate calibration, (1) an approved calibration procedure must be specifically referenced by (2) knowledgeable personnel using (3) equipment specified in the procedure (or adequate substitutes with required functions, ranges, and accuracies). Draft procedures may be used to perform calibrations, provided the procedures have been marked "DRAFT" and approved by the responsible TSD supervisor. Final approval of calibration procedures require signature of the TSD department head or his designee and the division QAS. If no procedure is available for an M\&TE item, vendor- or industry-approved general procedures will be used to calibrate the M\&TE after the procedures are reviewed for adequacy by the shop supervisor.

B. Although the maintenance supervisor is expected to assist the custodian/user in determining the extent of maintenance and required calibration to be performed, the decision to calibrate and the limits of calibration are the ultimate responsibility of the custodian/user.

C. The equipment required to calibrate an item shall be listed in the individual calibration procedure. Other approved equipment having the necessary characteristics such as functions, ranges, and accuracies may be used to perform a calibration even though that equipment may not have all of the characteristics of the listed item.

D. M\&TE and calibration standards are selected to provide suitable accuracy, range, stability, and resolution to meet the requirements of the intended use. Accuracy ratios between standards and devices under test should be maintained at 4:1 where practical. Calibrations performed at accuracy ratios less than 4:1 should employ statistical methodologies that verify that accuracy transference meets specified levels of measurement assurance.

It is important to note that good judgment must always be applied in calibrating equipment. Whether or not a piece of standard M\&TE is of adequate quality and accuracy to make reasonable measurements should be apparent to an experienced technician or supervisor. An essential criterion for calibration is that the equipment in question be sufficiently stable and accurate to perform its intended function. 


\subsection{EXCEPTIONS ' $O O$ PERIODIC CALIBRATION REQUIREMENTS}

Certain types of M\&TE do not require periodic calibration.

A. M\&TE that is seldom used but must be calibrated before use.

B. M\&TE that requires initial calibration only.

C. M\&TE identified as "calibration not required" (CNR), category A, does not require calibration because it does not provide quantitative measurement information (i.e., information obtained by its use is of a gross nature such as verifying power on or off).

The work center supervisor and the M\&TE custodian/user are responsible for determining calibration exceptions.

\subsection{LIMITED CALIBRATION}

In some situations, the work center may be authorized to perform a limited calibration. The work center supervisor may require written authorization from the custodian/user to perform a limited calibration.

\subsubsection{Limited Shop Capability}

When a work center does not have the capability to calibrate the full range of specifications contained in the calibration procedure, the work center supervisor shall advise the custodian/user of the extent of available services. The custodian/user shall then determine whether the available services meet measurement needs. If the limited calibration services will not meet the needs, the custodian/user shall advise the work center, and action shall be taken to obtain the necessary capabilities

\subsubsection{Limited User Requirements}

When a user requires less than the full capability of the instrument, the user shall specify the desired calibration points or ranges to the responsible work center. The work center supervisor or calibration technician shall clearly identify the points or ranges on the calibration record and shall provide a copy of the calibration data to the custodian/user unless otherwise directed.

\subsubsection{Instrument Limitation}

When a function, range, or specification on a multifunction instrument cannot be economically restored to its original design specifications, the work center supervisor shall advise the custodian/user of the condition. The custodian/user shall then determine whether the missing function is necessary and whether to permit a limited calibration or to replace the item.

In any case, the category B label (Sect. 4.2) shall be marked "SPECIAL" if the calibration is limited in any way. 


\subsection{CALIBRATION INTERVALS}

The established calibration interval is determined by the length of time the equipment should maintain its accuracy and perform its intended function. These intervals are established and modified as necessary.

A. The maximum calibration interval for new M\&TE is 12 months if no interval is recommended by the manufacturer. A calibration interval may be changed as a result of activity, applications, or maintenance history. Recall may be staggered to maintain an even work load in the work center. Users may request shorter intervals between calibrations to meet system or project requirements.

B. Custodians/users may request recalibration any time there is reason to question the accuracy of an instrument. Items that have been exposed to rough handling, overload, or other severe conditions shall be immediately identified and recalibrated before further use, regardless of the scheduled calibration date.

C. Calibration intervals for safety instruments are identified in their respective safety documents.

\section{CALIBRATION GRACE PERIOD}

The calibration of equipment shall be performed in accordance with a predetermined schedule. Extensions to the interval (grace periods) up to $25 \%$ of the calibration interval may be given. If the grace period is preempted by a Department of Energy order, law, safety document, or regulation, the exception shall be documented and the new requirements defined. Grace periods for safety class instruments are defined in their respective documents.

\subsection{CALIBRATION DEVIATIONS}

The Deviation Request, Form UCN-5458A, shall be completed in accordance with instructions on the back of the form for the following situations:

1. instrument is removed from calibration recall by the custodian/user;

2. instrument calibration is refused by custodian/user but instrument is not to be removed from recall system; and

3. calibration period is extended as a result of workload considerations and/or equipment is unavailable at scheduled recall date.

The work center supervisor shall

1. complete the Deviation Request form; 
2. file a copy of the completed form at the work center and submit a copy to the custodian/user for signature; and

3. upon receipt of the signed copy from the custodian/user, replace the file copy with the signed copy.

\subsection{CARE OF MEASURING AND TEST EQUIPMENT}

Custodians/users are responsible for the proper handling, storage, care, use, and cleanliness of M\&TE.

A Items of M\&TE shall be handled in such a way as to protect the condition and integrity of equipment regardless of its physical appearance.

B. It is the responsibility of the custodian/user to ensure that M\&TE is properly cleaned and tagged to indicate freedom from all contamination before transport to the responsible work center.

C. Calibration work centers shall tag or segregate out-of-calibration M\&TE to prohibit unauthorized use.

\subsection{MEASURING AND TEST EQUIPMENT WARRANTIES}

M\&TE is frequently covered by a provisional warranty from the manufacturer. Such warranties vary in length of coverage and specific service or maintenance coverage as well as in provision for correction of deficiencies in design, material, or workmanship that does not meet M\&TE performance specifications.

A. The work center supervisor is authorized to use the manufacturer's calibration certification on new M\&TE to establish the first calibration cycle and shall affix a category B label, provided it can be verified that the device was in acceptable condition when received and put into service.

B. Upon receipt of new equipment, the work center shall

1. determine the warranty expiration date,

2. calibrate equipment if required, and

3. return defective equipment under warranty to the custodian/user with technical information relative to the defect or to the vendor for warranty repair. 


\section{CALIBRATION LABEIS AND FORMS}

\subsection{PREPARATION AND USE OF CALIBRATION FORMS AND LABEIS}

All instruments for which the TSD has calibration responsibility shall be

A. identified with a unique identification number,

B. recorded in inventory as specified in Sect. 10 of MIDAS, and

C. labeled with a calibration label filled out in ink, which withstands the effects of the operating environment to which it will be subjected.

Note that under no circumstances shall information on calibration labels be altered. When a change in label information is required, remove and destroy the old label and affix a new label that displays the proper information.

\section{MEASURING AND TEST EOUIPMENT CALIBRATION LABEL}

The category A label shown in Fig. 4 shall be affixed to those items of M\&TE identified as "calibration not required" (CNR). The organization that owns CNR equipment is responsible for affixing this label to the M\&TE.

$\frac{\text { OAML MQTE }}{\text { CATEConY A }}$

Fig. 4. Category A calibration label.

Category B (calibration recall program) label (UCN-14883) shown in Fig. 5 shall be completed and affixed to standards and M\&TE calibrated by the responsible work center. If labels or tags are not practical, a facility logbook, technical notebook, or report of instruments calibrated may be used to record calibration status. The calibration technician shall complete the label in nonsmearing permanent ink in the following manner:

A. Identification number. Enter the identification (ID) number recorded in the MIDAS system on the equipment being calibrated.

B. Date: Enter the date the M\&TE was calibrated. When authorized to use manufacturer's calibration, use the date on the manufacturer's certificate rather than the date the unit was placed into service. 
C. Calibrated by: The badge number of the calibration technician shall be entered in this block. The I\&C calibration technician shall enter a check in the block that appropriately identifies the work center.

D. Special: This block shall be used to bring to the attention of the user that the M\&TE has a limited or special-case calibration.

E. Recall date: Enter the month and year in which the equipment is due for calibration. The calibration due date shall be obtained from the calibration work request or computed from the assigned calibration interval and start month on instrument inventory. Items calibrated and not on program recall shall be marked "NONE."

F. For calibration information call: Enter the phone number of the work center performing the calibration.

\begin{tabular}{|c|c|c|}
\hline \multicolumn{3}{|c|}{ - METE } \\
\hline \multicolumn{3}{|c|}{ 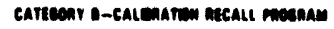 } \\
\hline \multicolumn{3}{|c|}{ DOENTIFICATION NO } \\
\hline \multirow{2}{*}{ CAllonateo } & $18 \mathrm{C}$ & Dall \\
\hline & & ACCACIOATI \\
\hline$\square$ icos & & 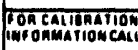 \\
\hline $0 \cdots$ & $\square^{\text {shors }}$ & \\
\hline$\square$ guasity & $\square \sec$ cial & weat \\
\hline
\end{tabular}

Fig. 5. Category B calibration label.

Category $\mathrm{C}$ (calibration by user) label shown in Fig. 6 shall be affixed to those items of M\&TE which are to be calibrated by or upon request of the custodian/user, who is responsible for identification and labeling.

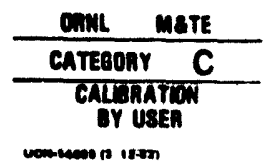

Fig. 6. Category C calibration label.

\section{PLACEMENT OF CALIBRATION LABEIS}

Calibration labels shall be affixed to a clean surface in a conspicuous area on the equipment. On small items, the label may be affixed to a tag and displayed by hanging on the equipment in an obvious and secure fashion, or the label may be placed in a container or cabinet that evidences the label and its association with the specific item being identified. The calibration label may be affixed to the side or back panel of interchangeable plug-ins. If the label cannot be placed on the front panel or if a tag 
would interfere with the operation of the plug-in, the size of the tag may be reduced by trimming. Trimmed tags must continue to display the ID number and recall date. All out-dated labels shall be removed. On complex M\&TE such as test stands and checkout consoles, one calibration label for the end item will suffice for all items that are an integral part of the equipment.

\subsection{CALIBRATION RECORD}

The I\&C calibration record (UCN-10600) (Fig. 7) or data sheet shall be completed for M\&TE calibrated by the work center technician to show the actual values of the parameters checked. The work center shall store and be able to retrieve the calibration record, and a copy may be attached to the equipment. The calibration record shall be in ink, legible, neat, and unaltered (no correction fluid). Errors should have a line drawn through, be initialed, and have correct data written in.

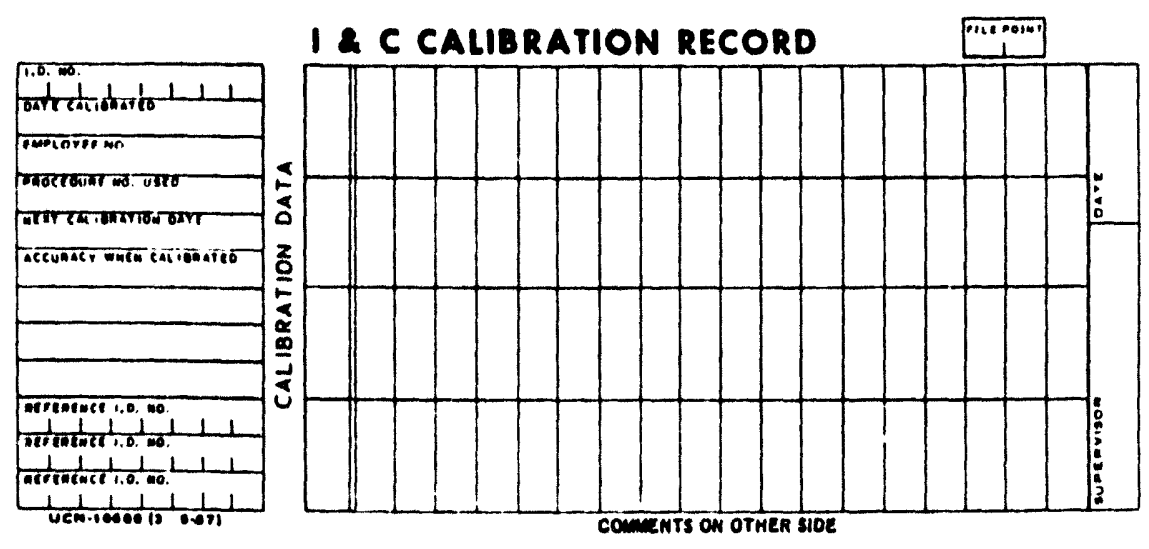

Fig. 7. Calibration record (UCN-10600).

The calibration record shall be completed as follows:

A. Identification number: Enter the ID number assigned the M\&TE.

B. Date calibrated: Enter the date on which the M\&TE was calibrated.

C. Employee number: The badge number of the calibration technician shall be entered in this block.

D. Procedure number used: Enter the calibration procedure number assigned to the M\&TE. 
E. Next calibration date: Enter the next calibration due date, determined by the assigned calibration interval as described in item $E$ of Sect. 4.2. Items calibrated and not on program recall shall be marked "NONE."

F. Accuracy when calibrated: Accuracy shall comply with manufacturer's specifications unless otherwise noted. For limited calibrations, identify the parameter(s) calibrated and accuracy required.

G. Reference identification number. Enter the ID number(s) of the standard(s) used to perform the calibration.

H. Calibration data: Indicate appropriate column headings and units for the calibration parameters. Recorded information shall include "as-found" and "as-left" data as well as errors calculated.

I. File point: Enter the appropriate file point.

The technician performing the calibration shall sign and date the calibration record or data sheet after the calibration is completed, and the supervisor or designated representative will review for completeness and file.

When the calibration data cannot be entered on the I\&C calibration record or data sheet, all other pertinent information shall be entered on the I\&C calibration record with a note across the data entries indicating the location of the actual calibration information.

NOTE: Enter the work request number for the job in the space above the M\&TE ID number.

\subsection{MEASURING AND TEST EQUIPMENT CALIBRATION CORRECTION RECORD}

A chart or graph shall be made available, when requested by the using organization, to show the correction that must be applied to the indicated reading to obtain the actual value.

\subsection{COMPUTERIZED AND MANUALLY PREPARED CALIBRATION DATA}

Computerized or manually prepared calibration or correction data may be used as the calibration record, provided a calibration record (UCN-10600) is completed with a notation identifying the location of the calibration data. In certain locations, a computer data sheet is generated and stored as the calibration record; Form UCN-10600 is not utilized. 


\section{CAIIBRATION REPORTS}

The TSD MAJIC system collects maintenance information on M\&TE selected for calibration recall and provides computer-generated reports for control. Reports are available to identify current custodian, location of equipment, calibration interval, and next recall date. Refer to the MIDAS manual ${ }^{1}$ for specific calibration reports available. 


\section{REFERENCE}

1. C. T. Stansberry, S. M. Odom, and C. D. Martin, Maintenance Information and Data Acquisition System (MIDAS), ORNL/TM-11287, Oak Ridge National Laboratory, 1989. 


\section{INTERNAL DISTRIBUTION}

1. C. G. Allen

2-11. K. L. Allison

12. A. J. Beal

13. B. A. Benen

14. H. R. Brashear

15. R. Borum

16. B. L. Carpenter

17. T. E. Chambers

18. C. R. Cinnamon

19. J. L. Cotter

20. D. F. Craig

21. D. M. Duncan

22. R. P. Effler

23. R. E. Fenstermaker

24. H. C. Ford

25. D. N. Fry

26. J. L. Hammontree

27. R. D. Harris

28. J. E. Jones, Jr.

29. M. Kreiger

30. C. W. Kunselman

31. W. L. Marsh (MIT-118)
32. D. W. McDonald

33. T. J. McIntyre

34. L. E. McNeese

35. R. McKeehan

36-40. D. R. Miller

41-45. A. J. Millet

46. D. G. Prater

47. R. P. Rosenbaum

48. C. S. Sims

49. C. T. Stansberry

50. J. O. Stiegler

51. T. E. Swabe

52. C. W. Tompkins

53. E. P. Trowbridge

54. ORNL QA Manager

55-56. Central Research Library

57. Y-12 Document Reference Section

58. I\&C Division Publications Office

59-60. Laboratory Records

61. Laboratory Records-Record Copy

62. ORNL Patent Section

\section{EXTERNAL DISTRIBUTION}

63. R. E. Williams, DOE-ORO, Y-12, Oak Ridge, TN 37831-8179

64. Assistant Manager for Energy Research and Development, DOE-ORO, P.O. Box 2001, Oak Ridge, TN 37831-8600

65. B. Chexal, Electric Power Research Institute, 3412 Hillview Avenue, Palo Alto, CA 94303

66. V. Radeka, Brookhaven National Laboratory, Instrumentation Division, 535-B, Upton, NY 11973

67. M. M. Sevik, Carderock Division, Naval Surface Warfare Center, Code 1900, Bethesda, MD 20084-5000

68. R. M. Taylor, Leeds and Northup, Sunneytown Pike, North Wales, PA 19454

69-70. Office of Scientific and Technical Information, U.S. Department of Energy, P.O. Box 62, Oak Ridge, TN 37831

71. W. D. Siemens, Sandia National Laboratory, P.O. Box 5800, Org 33, Albuquerque, NM 87185 

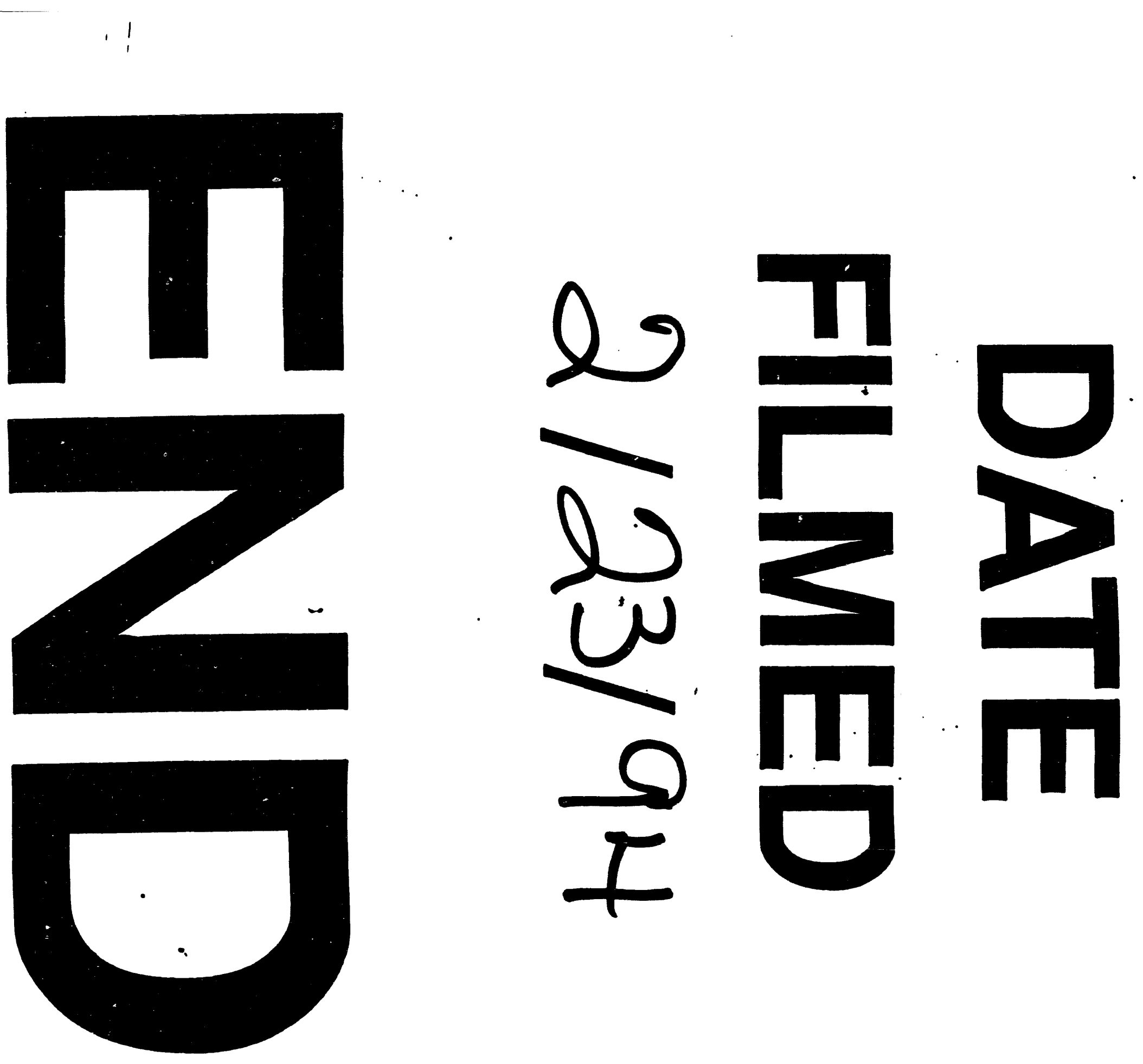


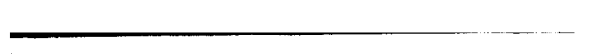
. 